\title{
A BURGUESIA INDUSTRIAL BRASILEIRA E SUAS RELAÇÕES COM O ESTADO NO CONTEXTO DO DESENVOLVIMENTO ECONÔMICO PERIFÉRICO DO CAPITALISMO NACIONAL.
}

\author{
Marco Antonio Bestetti Paccola* \\ *Professor: Universidade Tecnológica Federal do Paraná \\ marcopaccola@utfpr.edu.br
}

\section{RESUMO}

A pesquisa visa reformular a interpretação corrente acerca das origens e do papel desempenhado pela burguesia industrial brasileira durante o processo de transformação da estrutura econômica, política e social do país. Reinterpretando as relações que esta classe manteve com o Estado e os demais setores da economia na consecução do projeto de desenvolvimento brasileiro a partir da década de 1930. Para isso, pretende-se incorporar à analise a influência exercida pela inserção subordinada e tardia do país no sistema capitalista global e as condicionantes que esta inserção estabeleceram ao desenvolvimento nacional. Buscando analisar como as classes nacionais manejaram com esta inserção e buscaram implementar seus projetos de desenvolvimento frente a este contexto, estabelecendo novos tipos de relações entre as classes, tanto no âmbito nacional quanto internacional.

Palavras chave: burguesia industrial, política-econômica, desenvolvimentismo.

\section{INTRODUÇÃO}

Analisar o desenvolvimento do setor industrial no Brasil, assim como todos os condicionantes e consequências que estiveram presentes neste processo, constitui-se em tarefa de extrema complexidade. Isto porque, o desenvolvimento da indústria e mesmo do próprio sistema capitalista brasileiro, guardam enormes particularidades que os diferenciam dos processos observados nos países centrais e os afastam dos modelos teóricos estabelecidos a partir de uma visão de tipo ideal. Em primeiro lugar, a própria inserção subordinada do país na economia mundial capitalista, mediante um longo processo de colonização e exploração mercantilista. Segundo, o desenvolvimento do setor industrial tardio e sob condições históricas completamente diferentes daquelas experimentadas pelos países pioneiros deste processo. Entre outros, são condicionantes que influenciaram e continuam a influenciar a dinâmica econômica do país.

A sociologia brasileira tem buscado interpretar o processo de desenvolvimento do capital industrial no país, a partir da década de 1930. Após o surto que este setor observou neste período e as mudanças na política-econômica nacional, os estudos a respeito da indústria no país começaram a repercutir com maior intensidade. Com isso iniciou-se um profundo debate a respeito das origens deste processo e dos seus desdobramentos, debate este que se estende até os dias atuais e que continua levantando controvérsias. Entretanto, outro aspecto deste processo, de extrema importância para a compreensão do desenvolvimento capitalista brasileiro, tem sido pouco debatido no âmbito da Sociologia atualmente. Trata-se das origens da própria burguesia industrial 


\section{SEMINÁRIO DE PESQUISA EM CIÊNCIAS HUMANAS - SEPECH \\ Humanidades, Estado e desafios didático-científicos \\ Londrina, 27 a 29 de julho de 2016}

brasileira e principalmente do papel desempenhado por ela na transformação da economia nacional e sua relação com as demais classes e o Estado.

As primeiras interpretações sobre o este tema ${ }^{1}$, sustentaram a tese que, assim como a própria indústria nacional nascente teria se originado a partir dos excedentes de capitais e dos "encadeamentos" "provenientes do setor cafeeiro, a burguesia industrial teria a sua raiz na burguesia agrário-exportadora, principalmente a cafeeira. Seja através da diversificação de seus investimentos como forma de amenizar a crise de superprodução do café, seja através das atividades de suporte à produção agrícola, os cafeicultores estariam na origem da constituição da burguesia industrial no país.

Além de Celso Furtado e Caio Prado Jr. outros autores que avançaram na análise das origens do setor industrial como: Octávio Ianni (1963), Albert Hirschman (1965), Fernando Henrique Cardoso (1969), Maria da Conceição Tavares (1972), Wilson Cano (1998), Sérgio Silva (1976), João Manuel Cardoso de Mello (1984), apenas para citar alguns, aprofundaram o pressuposto de que a burguesia industrial teria se originado, com algumas poucas variações, no setor agrário, apesar de suas contradições e antagonismos. Estes estudos, apesar de guardarem diferenças a respeito dos aspectos da industrialização brasileira e de como determinados setores das oligarquias agrárias teriam se metamorfoseado em uma nova burguesia industrial, serviram de alicerce para que a tese se consolidasse. Dessa forma, esta interpretação sociológica a respeito do setor industrial brasileiro tornou-se praticamente hegemônica, levando a tese de que a burguesia industrial teria se originado a partir da oligarquia cafeeira a transformar-se em um consenso que permanece sendo reproduzido pelos estudos mais recentes, sem que se faça uma análise mais detida sobre o assunto.

\section{O DEBATE SOBRE AS ORIGENS DA BURGUESIA E SUA RELAÇÃO COM O ESTADO}

A partir deste paradigma, formularam-se diversas teorias a respeito da atuação da burguesia industrial no processo político-econômico brasileiro, buscando interpretar como esta classe se organizou para levar adiante seus projetos, sua atuação junto ao Estado, na política, na sociedade civil etc. Fernando Henrique Cardoso ${ }^{3}$, Nelson Werneck Sodré ${ }^{4}$, Oliveira Vianna ${ }^{5}$, foram alguns dos autores que se debruçaram sobre esta questão. Também Florestan Fernandes ${ }^{6}$, que apesar de concordar com a origem da burguesia industrial a partir da oligarquia cafeeira, alerta para o fato de que esta classe sofreu determinante influencia ideológica de parcela dos imigrantes europeus atraídos pelo surto do café no país:

\footnotetext{
${ }^{1}$ Veja-se: FURTADO, Celso. Formação econômica do Brasil. São Paulo: Nacional, 2003. PRADO Jr., Caio. História Econômica do Brasil. São Paulo: Brasiliense, 1949.

${ }^{2}$ HIRSCHMAN, Albert Otto. Política econômica na América Latina. Rio de Janeiro: Fundo de Cultura, 1965.

${ }^{3}$ CARDOSO, Fernando Henrique. O empresário industrial e o desenvolvimento econômico do Brasil. Tese (Livre-Docência). São Paulo: FFLCH/USP, 1963.

4 SODRÉ, Nelson Werneck. História da burguesia brasileira. 2a. Ed. Rio de Janeiro: Civilização Brasileira, 1967.

${ }^{5}$ VIANNA, Oliveira. História social da economia capitalista no Brasil. Rio de Janeiro, EDUFF. 1987.

${ }^{6}$ FERNANDES, Florestan. A Revolução burguesa no Brasil: Ensaio de interpretação sociológica. Rio de Janeiro, Zahar. 1976.
} 


\section{SEMINÁRIO DE PESQUISA EM CIÊNCIAS HUMANAS - SEPECH \\ Humanidades, Estado e desafios didático-científicos \\ Londrina, 27 a 29 de julho de 2016}

Esse processo se intensifica nas regiões que se beneficiam do surto econômico provocado pelo café ou pela imigração (em alguns lugares, os dois fenômenos somaram seus efeitos inovadores). De tais estratos é que procediam os representantes mais característicos e modernos do "espírito burguês" - os negociantes a varejo e por atacado, os funcionários públicos e os profissionais "de fraque e cartola", os banqueiros, os vacilantes e oscilantes empresários das indústrias nascentes de bens de consumo, os artesãos que trabalhavam por conta própria e toda uma massa amorfa de pessoas em busca de ocupações assalariadas ou de alguma oportunidade de enriquecer. (FERNANDES, 1976, p. 28).

É preciso, contudo, alentar para o fato de que autor esta considerando neste caso o "espírito burguês", ou seja, o conjunto de ideias e atitudes que dão corpo a um determinado tipo de organização econômica, não podendo confundir esta definição com a formação da classe propriamente dita.

Os autores estabeleceram então, seguindo a tradição de relacionar a burguesia industrial com a oligarquia cafeeira, a tese de que esta burguesia não foi capaz de levar adiante o projeto de reestruturação da sociedade brasileira, logrando efetuar uma completa "revolução burguesa" no país, como ocorrera nos países de capitalismo desenvolvido". Ao contrário do que ocorrera naqueles países, no Brasil a burguesia nascente não estava em completa oposição à classe então dominante da sociedade, as oligarquias agrárias, pelo contrário, manteve com ela estreitos vínculos provenientes de sua raiz comum. É isto o que, segundo Segundo Barbosa (2013, p. 397) Vianna e Cardoso tentam demonstrar em suas análises, quando salientam a mentalidade arcaica da burguesia brasileira:

Para Vianna, o pequeno número de sociedades anônimas em nossa estrutura industrial e o predomínio das empresas de organização familiar, nas quais a figura do patriarca prevalecia sobre a do empresário, era o exemplo típico da "refratariedade das nossas burguesias do dinheiro aos métodos e técnicas do grande capitalismo industrial".

$[\ldots]$

Segundo Cardoso (1963), predominava no Brasil a categoria dos "capitães de indústria", senhores absolutos dos rumos tomados por seus negócios, pouco afeitos a inversões substanciais, visando à melhoria da base técnica de suas empresas e bastante propensos a se guiarem no mercado "pela experiência" antes que pelo planejamento racional. Para esse autor, a prevalência desse tipo de administração rigorosamente pessoal - ou, no limite, familiar - das empresas acabou por gerar vicissitudes e impor restrições ao ritmo do processo de industrialização em curso desde o início dos anos 30.

A partir destas teses, fortaleceu-se a concepção de que a burguesia industrial brasileira constituía-se em uma classe anômala, desorientada, tímida, fraca e incapaz de levar a cabo um processo de reestruturação da economia pautado nos seus próprios

\footnotetext{
${ }^{7}$ BARBOSA. Agnaldo Sousa. Revisitando a literatura sobre o empresariado industrial brasileiro: dilemas e controvérsias. In. Caderno CRH, Salvador, v. 26, n. 68, p. 391-406, Maio/Ago. 2013.
} 


\section{SEMINÁRIO DE PESQUISA EM CIÊNCIAS HUMANAS - SEPECH \\ Humanidades, Estado e desafios didático-científicos \\ Londrina, 27 a 29 de julho de 2016}

interesses e de confrontar os interesses da oligarquia agrária. Motivo pelo qual, o projeto de industrialização brasileiro precisou contar com a atuação decisiva do Estado para sua efetivação. Assim, a maior parte das pesquisas que se desenvolveram a partir de então destacavam a decisiva atuação do Estado na transformação do capitalismo brasileiro, principalmente a partir de 1930 e praticamente desconsideravam a participação da própria burguesia industrial nesse processo. Francisco Weffort ${ }^{8}$, Sonia Miriam Draibe ${ }^{9}$, Pedro Cezar Dutra Fonseca ${ }^{10}$, procuraram demonstrar como a participação estatal foi decisiva neste contexto:

É necessário enfatizar, então, que a direção impressa pelo Estado à sua ação econômica contemplou, desde os anos 30, um projeto de desenvolvimento do capitalismo, de sua forma e ritmo, no sentido do avanço da industrialização e num quadro geral de definição da autonomia nacional. O formato e a dinâmica do aparelho econômico do Estado expressarão aquele projeto assim como revelarão os limites impostos à autonomia do Estado por sua "substancia social". (DRAIBE, 1985, p. 100).

Aceitando a tese de que o Estado desempenhou um papel preponderante durante o desenvolvimento da indústria brasileira, e, consequentemente, na revolução industrial que logrou transformar a estrutura produtiva nacional e estabelecer as bases para a consolidação de um sistema capitalista moderno no país. É preciso considerar que o Estado é parte importante do processo de desenvolvimento capitalista, visto que, este pressupõe a organização do sistema para a acumulação de capital, do qual estão presente e fazem parte os meios de produção, as forças produtivas e o próprio capital. Sendo que, a composição do sistema não se encerra no setor privado, mas transborda as fronteiras do setor público, necessita da atuação deste na organização dos agentes presentes neste sistema. Como ressaltou Ianni (1971, p. 6): "Este é o âmbito em que se constituem e operam as condições "não econômicas" indispensáveis à própria organização e reprodução das forças produtivas". Ou seja, o Estado possui invariavelmente um papel importante na configuração de um sistema capitalista, pois constitui-se em uma parte indispensável deste, atuando decisivamente na estruturação da ordem imaterial deste novo sistema. Em outras palavras, seria impossível dissociar o desenvolvimento capitalista da ação do Estado, uma vez que, este desenvolvimento pressupõe a incorporação do setor público como mecanismo de atuação na sociedade através da formatação de todo um aparato jurídico, político e ideológico que comporta a lógica organizativa do modelo capitalista. Dessa forma, é natural que o Estado, esteja presente no desenvolvimento do setor industrial brasileiro, contudo, o que se discute nesse sentido, é a penetração do Estado no âmbito da Estrutura do sistema capitalista, atuando diretamente na base material do sistema e gerando uma ampliação de suas atividades, que, segundo a interpretação predominante, desembocaria em um Estado

\footnotetext{
${ }^{8}$ WEFFORT, Francisco Correia. O Populismo na política brasileira. Rio de Janeiro: Paz e Terra, 1980.

${ }^{9}$ DRAIBE, Sônia Miriam. Rumos e Metamorfoses: um estudo sobre a constituição do Estado e as alternativas da industrialização no Brasil (1930 - 1960). Rio de Janeiro: Paz e Terra, 1985.

10 FONSECA, Pedro Cezar Dutra. Vargas: O capitalismo em construção 1906-1954. São Paulo: Brasiliense, 1989,
} 


\section{SEMINÁRIO DE PESQUISA EM CIÊNCIAS HUMANAS - SEPECH \\ Humanidades, Estado e desafios didático-científicos \\ Londrina, 27 a 29 de julho de 2016}

excessivamente ampliado, desempenhando as funções que deveriam ser exercidas pela burguesia.

As teses que buscavam contestar esta visão preponderante obtiveram pouca visibilidade naquele período. Ainda na década de 1960, Luis Carlos Bresser Pereira publicou pesquisa sobre as origens dos empresários industriais paulistas, que buscava vincular a burguesia industrial, com os imigrantes de classe média no país:

As origens sociais dos empresários industriais paulistas são também claras. Apenas 3,9 por cento tiveram origem nas famílias "aristocráticas" ligadas ao comércio e à produção do café. Originados na classe alta inferior, constituída por famílias ricas mas sem origens nos barões do café, tivemos 21,6 por cento dos empresários. Na classe média superior, definida pela situação econômica média da família na época da infância ou adolescência do empresário e pela educação de nível superior do pai, tivemos apenas 7,8 por cento. Nas classes médias propriamente ditas, formadas principalmente por pequenos e médios empresários, originaram-se 50 por cento, enquanto apenas 16,7 por cento originavam-se na classe baixa, constituída principalmente por famílias pobres nas quais o pai tinha geralmente uma profissão braçal.

[...]

Esta pesquisa não deixa, portanto, qualquer dúvida. Os empresários industriais do Estado de São Paulo, onde se concentrou a industrialização brasileira, não tiveram origem nas famílias ligadas ao café. Originaram-se em famílias imigrantes principalmente de classe média. (PEREIRA, 1994, p. 6).

Warren Dean ${ }^{11}$ apesar de concordar com Bresser em relação à origem imigrante da burguesia industrial brasileira discorda deste, no que diz respeito à categoria desses imigrantes. Para Dean, o imigrante responsável por dar origem aos empreendimentos industriais no Brasil, diferenciava-se da grande maioria de trabalhadores imigrantes e tampouco pertencia à classe média, mas fazia parte de uma minoria que estava em posse de capital necessário para realizar tal empreendimento. Além disso, aponta para um processo de simbiose entre a recém-estabelecida burguesia industrial e os cafeicultores paulistas, através de alianças matrimoniais. Processo que concedia aos industriais a possibilidade de uma maior participação política e certo grau de status na sociedade, mas que, por outro lado, amarrava seus interesses aos interesses agrários ${ }^{12}$.

A partir da década de 1970, algumas análises viriam a contestar também a visão de que a burguesia industrial brasileira constituía-se numa classe impotente, dependente do Estado e com importância secundária no processo de transição econômica do Brasil. Estes trabalhos indicam a existência de um projeto político-econômico proveniente dos próprios industriais, que teriam assumido ainda um papel de relevo no processo de industrialização do país e consequente reestruturação do capitalismo nacional.

Sem subestimar o papel do Estado no processo, Ianni destacou que a burguesia industrial foi de crucial importância para a transição econômica que iniciaria a partir de

\footnotetext{
${ }^{11}$ DEAN, Warren. A industrialização de São Paulo. São Paulo: editora da universidade de São Paulo, 1971.

${ }^{12}$ Idem, p. 81-82.
} 


\section{SEMINÁRIO DE PESQUISA EM CIÊNCIAS HUMANAS - SEPECH \\ Humanidades, Estado e desafios didático-científicos \\ Londrina, 27 a 29 de julho de 2016}

1930 no Brasil. A partir do rompimento da hegemonia dos cafeicultores, os industriais puderam passar a reivindicar seus interesses na política nacional, o que de fato fizeram, utilizando-se do apoio dado pelo Estado para desenvolver seus projetos ${ }^{13}$.

Eli Diniz e Bresser Pereira ${ }^{14}$ também ressaltaram a participação da burguesia industrial nos rumos do desenvolvimento brasileiro, indicando que esta classe constituiu, junto com a burocracia pública, um pacto que se estendeu desde 1930 até a década de 1980 e que privilegiou o projeto de desenvolvimento nacional por meio da industrialização via substituição de importações.

Entre 1930 e 1980, o país industrializou-se e cresceu extraordinariamente sob o comando de uma coalizão política que teve, como principais atores, os empresários industriais e a burocracia pública, e, como estratégia de desenvolvimento econômico, o nacionaldesenvolvimentismo caracterizado pela substituição de importações e pela forte presença do Estado na economia. (PEREIRA, 1994, p. 8).

Seguindo esta vertente, Maria Antonieta Leopoldi contesta a tese de que os industriais não se envolveram na política nacional durante o processo de industrialização, preferindo reivindicar suas demandas junto ao Estado ao invés de tomar a frente de políticas públicas e participar efetivamente do planejamento econômico do país. Destaca, sobretudo, a participação desta classe na formulação de políticas a partir de 1930, através da participação direta de seus representantes em cargos do governo e/ou mediante a elaboração de projetos e assessoria a políticas econômicas ${ }^{15}$.

Francisco Oliveira critica a tese de que o capitalismo brasileiro teria desenvolvido-se a partir de um padrão dualista, no qual estariam em oposição os resquícios arcaicos de uma economia agrária baseada principalmente no domínio das oligarquias e na produção de produtos primários para o mercado externo e o setor "moderno", industrial substituidor de importações, baseado na burguesia e no mercado interno. Para o autor, as especificidades do desenvolvimento brasileiro estabeleceram um padrão particular de capitalismo, o qual edificou-se combinando os aspectos "arcaicos e modernos" da sociedade, que, apesar dos antagonismos existentes, complementam-se como setores interdependentes do capitalismo nacional ${ }^{16}$. Este padrão se constitui em função do contexto sob o qual o país se inseriu no sistema capitalista global, como economia periférica e de desenvolvimento tardio.

Aqui perfila-se um ponto essencial da tese: a de que, tomando como um dado a inserção e a filiação da economia brasileira ao sistema capitalista, sua transformação estrutural, nos moldes do processo pósanos 30 , passa a ser, predominantemente, uma possibilidade definida dentro dela mesma; isto é, as relações de produção vigentes continham

\footnotetext{
${ }^{13}$ IANNI, Octavio. op. cit. 1971 p. 14.

${ }^{14}$ BRESSER-PEREIRA, Luiz Carlos. DINIZ, Eli. Empresariado industrial, democracia e poder político. In. Novos estudos CEBRAP. n.84. 2009.

${ }^{15}$ Veja-se: BARBOSA. Agnaldo Sousa. 2013 op. cit. p. 403

16 OLIVEIRA, Francisco Maria Cavalcanti de. Crítica à razão dualista/O ornitorrinco. São Paulo, Boitempo, 2003. P. 40.
} 


\section{SEMINÁRIO DE PESQUISA EM CIÊNCIAS HUMANAS - SEPECH \\ Humanidades, Estado e desafios didático-científicos \\ Londrina, 27 a 29 de julho de 2016}

em si a possibilidade de reestruturação global do sistema, aprofundando a estruturação capitalista, ainda quando o esquema da divisão internacional do trabalho no próprio sistema capitalista mundial fosse adverso $^{17}$. (OLIVEIRA, 2003, p. 33).

$\mathrm{O}$ autor destaca o fato de que, dentro do contexto político-econômico, este modelo foi uma possibilidade e não um imperativo ao desenvolvimento nacional, o que deixa margem a certo grau de autonomia no direcionamento do padrão de acumulação nacional e reacende o debate acerca das disputas internas entre as classes e os setores nacionais pela hegemonia da sociedade e do papel da burguesia industrial neste processo.

Como é possível observar, a discussão que perpassa a temática da formação e atuação da burguesia industrial é extremamente controversa, entretanto, não se tem debatido esta questão nos estudos que se propõem a analisar a composição das classes no país ou a burguesia industrial atualmente, o que pode deturpar os resultados obtidos uma vez que, partem de um pressuposto não consensual para embasar suas teorias.

Apesar do debate que se realizou nesse sentido, permanece na sociologia o paradigma a respeito das origens agrárias da burguesia industrial, que, por constituir-se em uma classe atrofiada e dependente do Estado, teria desempenhado um papel secundário na economia brasileira.

\section{REAFIRMAÇÃO DAS ORIGENS AGRÁRIAS DA BURGUESIA}

A partir de uma nova configuração da política-econômica brasileira estabelecida em fins da década de 1980. Com o fim do modelo de desenvolvimento pautado no setor industrial e o redirecionamento da política-econômica no sentido de adequar o Brasil ao novo padrão de acumulação capitalista, a dinâmica de desenvolvimento e a luta de classes no país tomam uma nova forma.

Em virtude da grande crise pela qual o Estado passou nesse período, a capacidade do setor público levar a cabo um projeto de desenvolvimento foi erodida $\mathrm{e}$ com ela se rompe também o longo processo de desenvolvimento pautado no setor industrial. Abrindo assim, a possibilidade para a interiorização do modelo neoliberal, que já vinha ganhando força dentro de determinadas camadas da classe dominante no país e que era predominante na política dos principais países de capitalismo desenvolvido. A partir de então, o modelo econômico que se estabeleceu no país, retira o foco do desenvolvimento pautado na indústria, transferindo-o para o setor financeiro com predomínio dos rentistas, do capital internacional e dos bancos.

Diante disso, reafirmou-se a tese de que a burguesia industrial se constitui em uma classe dependente do Estado em vista da incapacidade de esta classe dar continuidade ao projeto de desenvolvimento que vinha sendo a base da economia do país até então, uma vez que a participação do Estado precisou ser drasticamente reduzida com a crise. O fracasso da burguesia industrial ao tentar reestabelecer o desenvolvimento econômico do país após a redemocratização e a crise do Estado coadunou com a crítica daqueles estudos que indicam uma incapacidade desta classe em

\footnotetext{
${ }^{17}$ Idem. p. 33.
} 


\section{SEMINÁRIO DE PESQUISA EM CIÊNCIAS HUMANAS - SEPECH \\ Humanidades, Estado e desafios didático-científicos \\ Londrina, 27 a 29 de julho de 2016}

assumir um papel hegemônico na sociedade e de direcionar o processo políticoeconômico do país, em função de uma dependência que se estabeleceu entre ela e o Estado. Assim, para esta vertente, a crise do Estado representou a crise do próprio modelo de desenvolvimento pautado no setor industrial e uma atrofia da burguesia industrial.

\section{CONTRAPONTO}

Contudo, apesar da crise do Estado e do fracasso da burguesia industrial em reestabelecer o desenvolvimento constituírem fatores determinantes para a mudança do padrão de acumulação no país, é preciso considerar que este processo se insere em uma dinâmica de transformação do próprio sistema capitalista que ocorreu de forma sistêmica entre os países e que não se restringiu a casos isolados. Esse processo de transição restringiu drasticamente as possibilidades de continuidade do modelo de desenvolvimento anterior. Sem subestimar a autonomia nacional nesta dinâmica, devese manter em mente que o país encontra-se inserido dentro deste sistema e que as transformações que ocorrem nele irão influenciar na organização interna da economia. Parece-nos, contudo, que estas condicionantes não são devidamente salientadas quando se procura compreender o esgotamento do modelo de desenvolvimento industrial brasileiro e a ineficácia da burguesia industrial em dar continuidade a este projeto.

A principal hipótese deste estudo busca uma nova interpretação da burguesia industrial brasileira como classe e das suas relações com o Estado, que não estaria esgotada pelas análises realizadas até o presente momento. Esta nova interpretação parte do pressuposto de que, em detrimento das particularidades observadas no desenvolvimento do capitalismo nacional e na formação das classes sociais que o compõem, em função da própria inserção diferenciada do país ao sistema capitalista global. A estrutura de classes e a forma como estas se empenharam na consecução de seus interesses adquiriu uma configuração particular, diferente da observada e analisada nos países de capitalismo desenvolvido, o que estaria na raiz dos principais equívocos dos estudos sobre as classes no Brasil. As relações entre o Estado e as classes sociais no país estão condicionadas ao contexto sob o qual o país esta inserido, sendo impossível desvencilhar a interpretação desta realidade. Sob esta conjuntura, a burguesia industrial brasileira precisou adaptar-se às condições que lhe foram impostas, não apenas pela estrutura econômica existente como pela inserção do país no capitalismo mundial, adquirindo uma constituição heterogênea durante sua composição. E não só a formação da burguesia como classe esteve restrita aos condicionantes estruturais da economia brasileira como também o desenvolvimento do capitalismo industrial no país precisou adaptar-se a esta realidade.

\section{REFERÊNCIAS}

ANDRADA, Leonardo Silva. Empresariado industrial e estratégias para o desenvolvimento: o IEDI no governo Lula. In: Encontro anual da associação nacional de pós-graduação e pesquisa em Ciências Sociais, v. 29, 2005. 


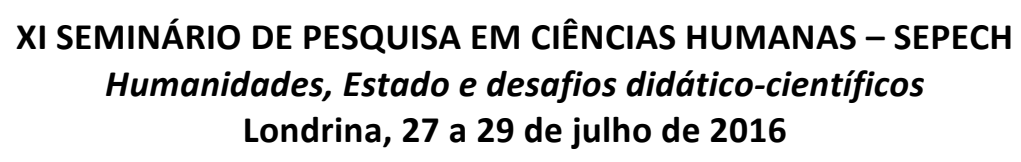

BAER, Werner. A economia brasileira. São Paulo: Nobel, 2002.

BARBOSA. Agnaldo Sousa. Revisitando a literatura sobre o empresariado industrial brasileiro: dilemas e controvérsias. In. Caderno CRH, Salvador, v. 26, n. 68, p. 391406, Maio/Ago. 2013.

BOITO Jr., Armando. Estado e burguesia no capitalismo neoliberal. In: Revista Sociologia e Política, Curitiba, 28, p. 57-73, jun. 2007.

CARDOSO, Fernando Henrique. O empresário industrial e o desenvolvimento econômico do Brasil. Tese (Livre-Docência). São Paulo: FFLCH/USP, 1963.

DEAN, Warren. A industrialização de São Paulo. Editora da Universidade de São Paulo. São Paulo 1971.

DINIZ, Eli. Empresário, estado e capitalismo no Brasil: 1930-1945. Rio de Janeiro: Paz e Terra, 1978.

DRAIBE, Sônia Miriam. Rumos e metamorfoses: Um estudo sobre a constituição do Estado e as alternativas da industrialização no Brasil 1930 - 1960. Rio de Janeiro: Paz e Terra, 1985.

FAUSTO, Boris. A revolução de 1930: Historiografia e História. São Paulo: Brasiliense, 1975.

FERNANDES, Florestan. A Revolução burguesa no Brasil: Ensaio de interpretação sociológica. Zahar, Rio de Janeiro 1976.

FONSECA, Pedro Cezar Dutra. Vargas: O capitalismo em construção 1906-1954. São Paulo: Brasiliense, 1989.

FURTADO, Celso. Formação econômica do Brasil. São Paulo: Nacional, 2003.

IANNI, Octavio. Estado e planejamento econômico no Brasil (1930 - 1970). Rio de Janeiro: civilização brasileira, 1979.

LEOPOLDI, Maria Antonieta. Política e interesses na industrialização brasileira: as associações industriais, a política econômica e o Estado. Rio de Janeiro: Paz e Terra, 2000 .

MAZZEO, Antonio Carlos. Burguesia e capitalismo no Brasil. Ed. Atica, 1988.

OLIVEIRA, Francisco Maria Cavalcanti de. A economia da dependência imperfeita. Rio de Janeiro: Graal, 1977.

São Paulo, Boitempo, 2003.

Crítica à razão dualista/O ornitorrinco. 
PEREIRA, Luiz Carlos Bresser. O empresário industrial e a revolução brasileira. In. Revista de Administração de Empresas. julho 1963.

Burocracia pública e classes dirigentes no Brasil. In.

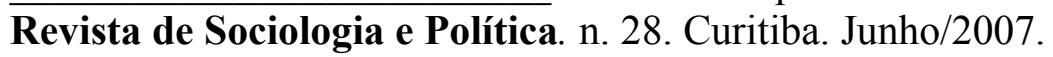

PEREIRA, Luis Carlos Bresser; DINIZ, Eli. Empresariado industrial, democracia e poder político. In. Revista Novos estudos. - CEBRAP, São Paulo, n. 84, 2009.

PRADO Jr., Caio. História Econômica do Brasil. São Paulo: Brasiliense, 1949.

SILVA, Sérgio. Expansão cafeeira e origens da indústria no Brasil. São Paulo: AlfaÔmega, 1976.

SODRÉ, Nelson Werneck. História da burguesia brasileira. Rio de Janeiro: Civilização Brasileira, 1967.

SUZIGAN, Wilson. Indústria Brasileira: Origem e Desenvolvimento. São Paulo: editora da Unicamp, 2000.

VERSIANI, Flávio Rabelo. MENDONÇA DE BARROS, José (eds.). Formação Econômica do Brasil: a Experiência da Industrialização. São Paulo: Saraiva, 1977.

WEFFORT, Francisco Correia. O Populismo na política brasileira. Rio de Janeiro: Paz e Terra, 1980. 